\title{
A Practical Development of Automated Cleaning System for Construction Aluminum Scaffolding Boards
}

\author{
Fumihiro INOUE*, Kyouichi HISHIKAWA*, Tatsuya WAKISAKA* \\ Manabu TANAKA** and Kaoru ENDO** \\ * Obayashi Corporation, Technical Research Institute, 4-640 Shimokiyoto, Kiyose-shi ,Tokyo \\ 204, JAPAN \\ ** Ebara Corporation, Haneda Plant, 11-1 Haneda-Asahi-cho, Ohta-ku, Tokyo 144, JAPAN
}

\begin{abstract}
Aluminum scaffolding boards are widely used as contemporary material at construction sites due to light weight. However it is important to carefully clean dirty aluminum boards with mud and concrete paste because they are scratched easily. This paper describes the development of an automated cleaning system to improve the work efficiency and not to damage the board. Two washing methods are applied in this system. In the first stage, high pressure water jets from the rotating nozzles take off heavy dirt on the front side of the board instantly. In the second stage, by soaking this board in a large water tank generating a high power ultrasonic vibration, light dirt on the back side of board is gradually removed. The cleaning process is automatically controlled by some conveyor and handling robots. The waste water discharged in each sections is recycled by the process of chemical precipitation and multi-stage filters.

Introducing this system to our Material-Equipment Center, more than daily specified pieces of aluminum board are cleaned carefully without damage, and the work environment is also improved considerably.
\end{abstract}

\section{INTRODUCTION}

At each building construction site, various kinds of contemporary materials, such as scaffolding board, pipe and several joints are applied in accordance with the work schedule. In general, at the end of site work, some of these materials are partly broken and become heavily dirty with mud, concrete paste, spray painting etc.. To utilize these materials for the next site again, it is required to repair the broken parts safely and to wash them well. A neglect in the inspection of contemporary material may result in unexpected and serious accidents.

Recently, many aspects of construction work have been automated to improve the work efficiency and to reduce the working cost. Due to these circumstances, automated cleaning systems for particular contemporary materials are developed by specialized makers, and some of them have been introduced already. But, since the types of contemporary materials are various, most of them are inspected and washed by man-power using simple machines, and 
these work environments are extremely hard. The number of worker in this job is dwindling every year and the age is becoming older. It is therefore required to improve the cleaning technique and to develop an automated cleaning System.

\section{ACTUAL SITUATION AND PURPOSE OF DEVELOPMENT}

Among the contemporary materials, aluminum scaffolding boards have been widely used instead of steel and wooden boards due to light weight, corruptproof material and easy processing. At the construction sites of Obayashi Corporation in the Kanto district, the scaffolding boards have all been changed to aluminum material and its total nearly amounts to more than 300 thousand pieces. Therefore, the management and inspection of them have become one of main jobs in the Material-Equipment Center.

The scaffolding boards from the construction site are heavily dirty with mainly concrete paste as shown in Figure 1. However, because aluminum boards are scratched easily by only a light shake, they cannot be put into the cleaning system for steel boards by utilizing mechanical vibration or pressing roller. Conventional washing methods for aluminum board are performed by chemical action. To put it briefly, by soaking the board with concrete pastes in a tank filled with acid lotion for a long time, the paste is gradually removed. By this method, if the concrete pastes adheres thickly and strongly on the board, it can not be dissolved sufficiently, and rather the board itself may dissolve and corrode by chemical reaction. The working cost a board is also expensive. And this method had no effect for another kinds of dirts except concrete paste. Thus, the most suitable cleaning technique hasn't necessarily been established yet.

The present paper, for the purpose of improving work efficiency and work environment, describes about a washing technique applied by both high pressure water jet and ultrasonic cleaning, and the development of an automated cleaning system for removing the concrete paste on the aluminum scaffolding board.

The specification and schematic picture of aluminum board are indicated in Table 1 and Figure 2 respectively.

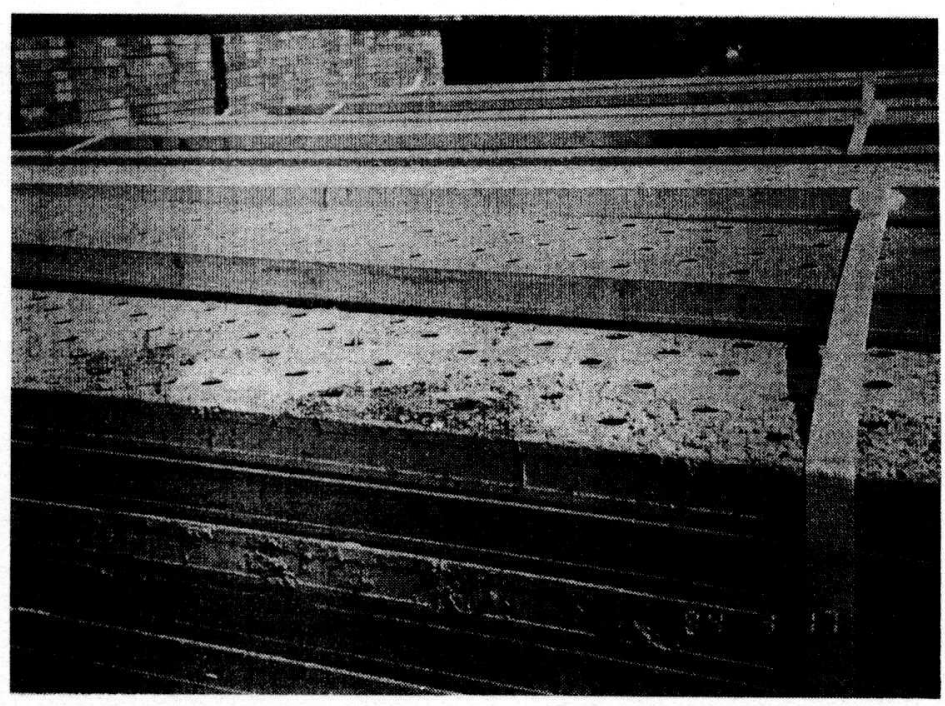

Table 1. Specification of Board

\begin{tabular}{|c|c|c|}
\hline Form & Weight & Load \\
\hline $\begin{array}{l}\text { Depth }: 29 \mathrm{~mm} \\
\text { Width }: 240 \mathrm{~mm}\end{array}$ & $10.1 \mathrm{~kg}$ & $120 \mathrm{~kg}$ \\
Length : $4000 \mathrm{~mm}$
\end{tabular}
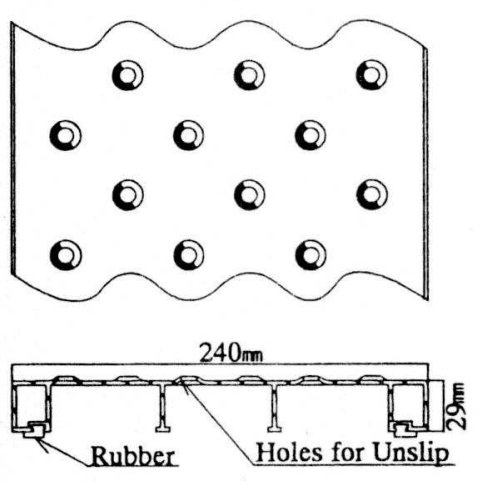

Figure 1 The Scaffolding Board Used at Cconstruction Site Figure 2 Schematic Form of Board 


\section{BASIC EXPERIMENTS FOR CLEANING METHOD}

\subsection{Water Jet Cleaning}

By utilizing a high pressure water jet striking the aluminum boards, the concrete paste is forcibly removed. Evaluating the most suitable pressure level and feed rate to separate only concrete paste, basic experiments are carried out with a single rotating nozzle. The center angle of the nozzle head is about 12 degrees, and the standoff distance is fixed at about $150 \mathrm{~mm}$ due to the relationship between the washing range and the number of nozzles. Test conditions of water jet are shown in Table 2 .

The effect of washing concrete paste is proportional to the levels of water pressure and is saturated at more than $40 \mathrm{MPa}$. In the pressure level from 60 to $80 \mathrm{MPa}$, microscratches are detected on the surface of aluminum board. Increasing the feed rate in the pressure level of $40 \mathrm{MPa}$, less than 60 $\mathrm{mm} / \mathrm{s}$ are the possible limit to wash sufficiently. An example of a water jet washing at a feed rate of $60 \mathrm{~mm} / \mathrm{s}$ is shown in Figure 3. At the pressure level of $20 \mathrm{MPa}$, concrete paste is considerably left and it can be struck off at more than $40 \mathrm{MPa}$ as seen clearly on both cleaning edges.

Similar experiments at the feed rate of $60 \mathrm{~mm} / \mathrm{s}$ are carried out with several kinds of dirt ; e.g. spray painting, plastic form and mud. The results are as follows: removing spray painting requires the pressure level of more than $100 \mathrm{MPa}$ and washing plastic form and mud are possible at less than 20 MPa. Except for spray painting, at the pressure level of more than $40 \mathrm{MPa}$ and the feed rate of less than $60 \mathrm{~mm} / \mathrm{s}$, most of the dirt on the board can be taken off well.

\subsection{Ultrasonic Cleaning}

Ultrasonic cleaning is generally recognized as one of the most precise washing techniques in the industrial field.The principle of this cleaning is that collapse energy of cavitation bubble, which is generated on the steady wave in the water by giving high frequency vibration, chips the dirt gradually. This energy is very high and it acts on all the surface of the material in the water..Therefore, the ultrasonic cleaning is suitable to wash material having many uneven surface. And also no influence on soft material such as rubber is one of the its characteristics. 


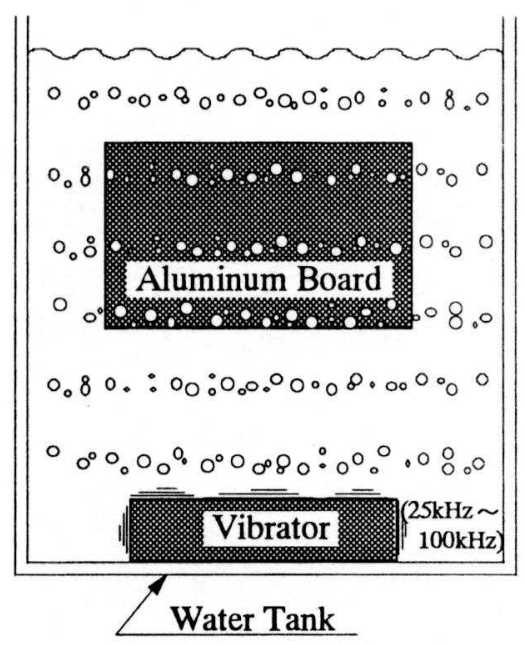

Figure 4 Test tank of Ultrasonic Cleaning

In this study, the effect of ultrasonic cleaning to chip the concrete paste is experimentally verified in the test tank as showing in Figure 4. The test specimen, which is about $30 \mathrm{~cm}$ square of aluminum board with much concrete paste, is soaked in the test tank generating the vibration of from $25 \mathrm{kHz}$ to $100 \mathrm{kHz}$. The relation between both the quantity of removal chips and washing time is indicated in Figure 5.

After 2 minutes, removal chips increase suddenly and they are saturated at about 6 minutes. Most of the concrete paste can be removed and there is no damage to the board. An example of the board washed by ultrasonic cleaning is presented in Figure 6. It is quite obvious that this washing is very effective. The less the air content in the water became, the more the chipping effect increases. Most of the concrete paste and other dirt on the both sides of the board can easily be chipped for a short time. However, as strongly fixed concrete paste doesn't remove completely, it is required to take it off before the ultrasonic cleaning.

For these results, first we remove the heavy dirt sufficiently by water jets and next, we wash the remaining dirt on both sides of the board by ultrasonic cleaning, which is assumed to be the most suitable cleaning technique for aluminum boards.

\section{DEVELOPMENT OF AUTOMATED CLEANING SYSTEM FOR ALUMINUM BOARD}

\subsection{Outline of Cleaning System}

Applying the two cleaning techniques indicated in chapter 3, an automated cleaning system is developed. In figure 7, the view of system and pictures of main parts are shown schematically. The whole of this system consists of the following four parts; water jet cleaning, ultrasonic cleaning, automated transportation system and water recycle system. 


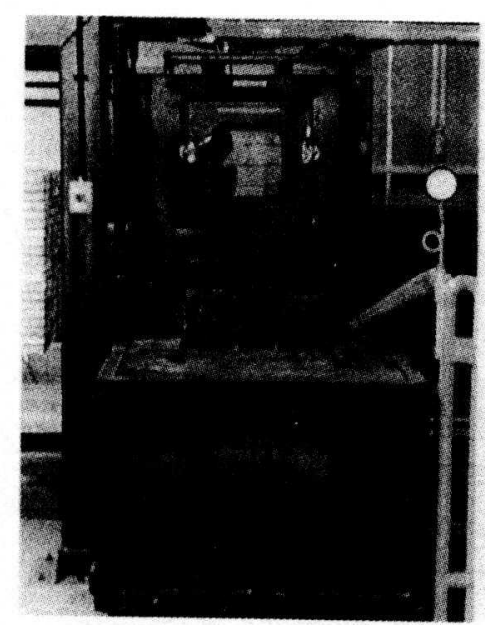

Washing Room of Water Jet
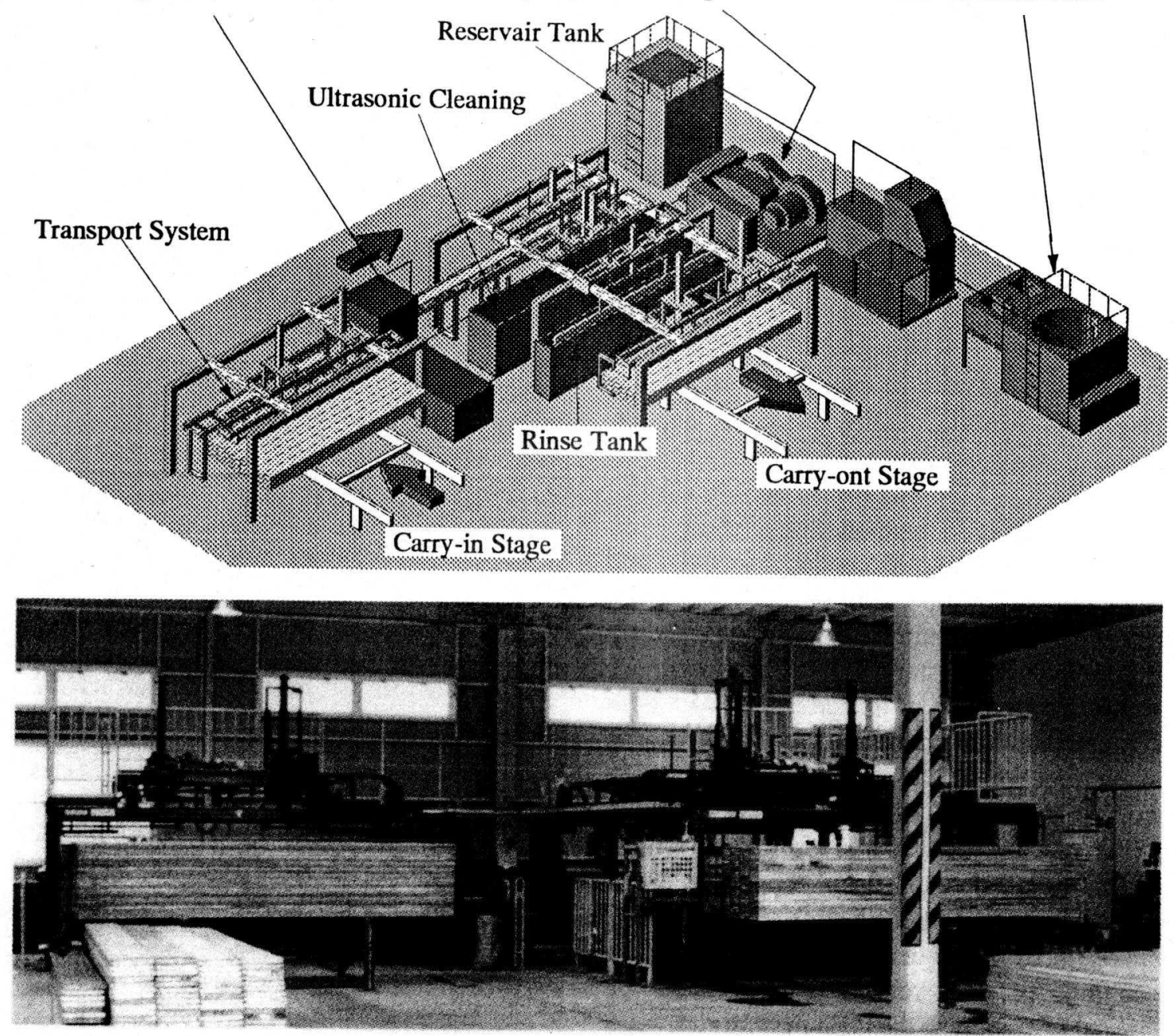

Figure 7 View of an Automated Cleaning System for Auminum Board 


\subsubsection{Water Jet Cleaning}

The aluminum board, which is carried to the washing room by a roller conveyor, is washed by water jets from six rotating nozzles successively. The pressure source of water jets are made with a high pressure pump. These rotating nozzles are arranged in the direction of front and both sides of the board as shown Figure 8 and the washing condition is schematically drawn in Figure 9. The washing room closes up tightly to prevent the jets rebounding and heavy noise, but the washing conditions are well observed through the window with tempered glass.

\subsubsection{Ultrasonic Cleaning}

The whole of aluminum board is washed by method of ultrasonic cleaning. View of the cleaning section is indicated in Figure 10. Fourteen sets of vibrators are installed at the bottom of a large cleaning tank, and where the high frequency vibration are generated. The inside of the cleaning tank, divided into three parts, each boards are washed three times in order. Heightening the washing effect, a high degassing water is supplied from deaeration facility, and the rate of cavitation outbreak is increased. Washing ability is said to depend on a degassing condition.

\subsubsection{Automated Transportation System}

Combining both the roller conveyor and some delivering robots installed on a moving girder, the aluminum board is automatically transported from start to finish. Figure 11 shows the example of transportation robots in this system. The cramping robot puts boards in the direction of horizontal and performs the carry-in and carry-out of them. The gripping robot catches the boards in the vertical direction and delivers them personally in the process of ultrasonic cleaning. These robots are operated by sequence control detecting the positions of each robots. By Selecting the manual operation at the center controller, each robot moves freely and concentrated cleaning of boards can be carried out.

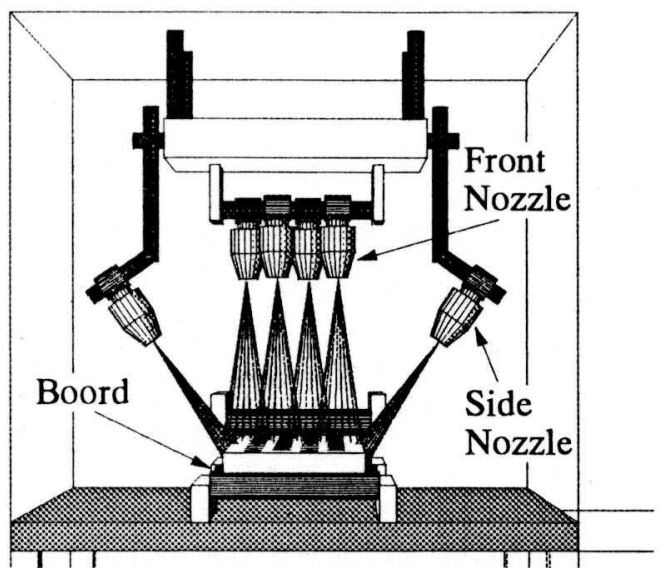

Figure 8 Arrangement of Rotating Nozzles

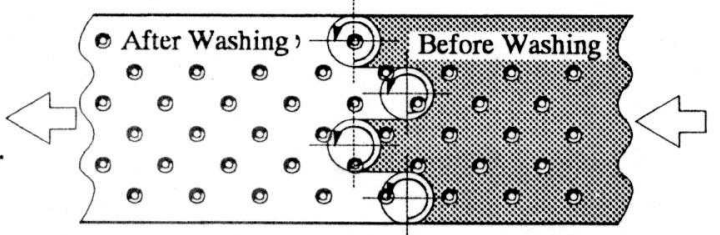

Figure 9 Sketch of Washing Condition

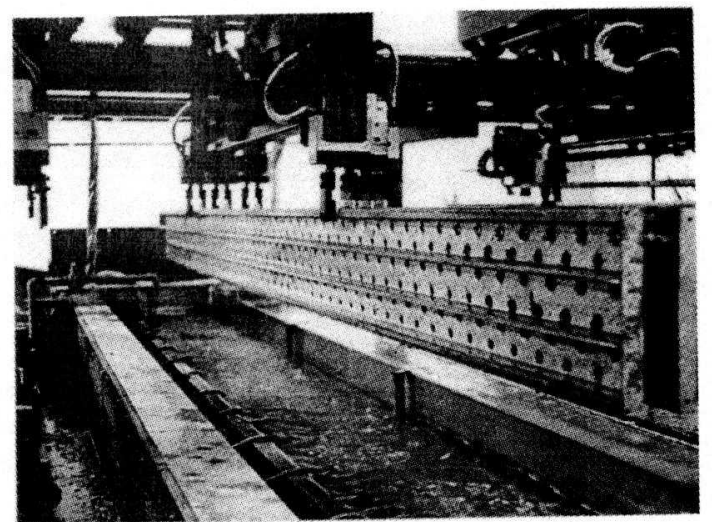

Figure 10 Washing by Ultrasonic Cleaning

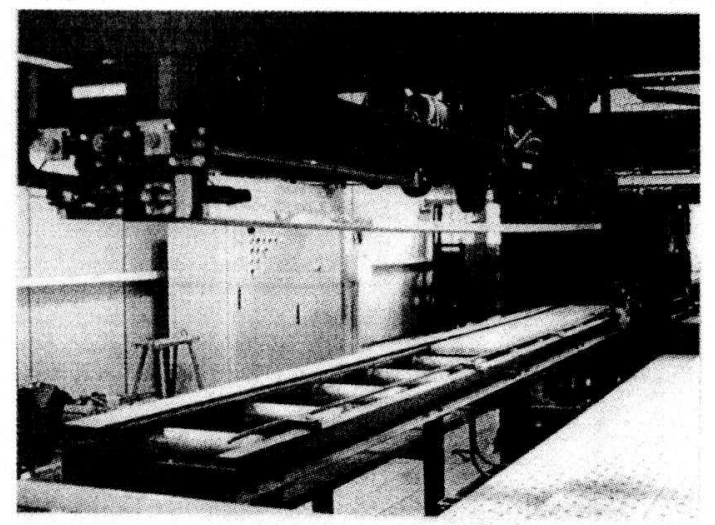

Figure 11 A exsample of Transpotation System 


\subsubsection{Water Recycle System}

The waste water discharged in each section is recycled by the purification facilities. The flowchart of water recycling process is indicated in Figure 12. Firstly, fine concrete chips are filtered by a mechanical screen of less than $250 \mu \mathrm{m}$ from the waste water, and further microscopic dust is chemically precipitated by pouring polymer. Finally, floating dust in the top layer of waste water are filtered by passing the dust through a mesh of less than $30 \mu \mathrm{m}$. The purified water in the system meets regulations in industrial water sufficiently

\subsection{Main Features of Cleaning System}

\subsubsection{Specification and Mode Setting}

Specifications of the cleaning system are presented in Table 3. The length of the scaffolding board and the feed rate of roller conveyor are selected by manual setting. In the standard setting, feed rate uses high mode, but in case of heavily dirty board, a low mode must be selected. On the carry-in stage, 3 units of boards, where one unit is a hundred boards, are put side by side. On a day, more than four hundred aluminum boards are washed successively.

\subsubsection{Cleaning Process}

Figure 13 shows a timechart of cleaning process at high mode. An aluminum board is cleaned through the several washing stages for about 6 minutes. At low mode, the cleaning time a board takes about 7 minutes. As soon as water jet cleaning is finished for a board, it is started for next board in succession. Ultrasonic cleaning is divided into triple process because the cleaning areas having a intense effect of ultrasonic vibration are with each process. In finishing process, the boards with dirt are completely rinsed. Completing the all cleaning process, the boards are piled up and stood in line at the carry-out stage where the finished boards are counted in the data base.

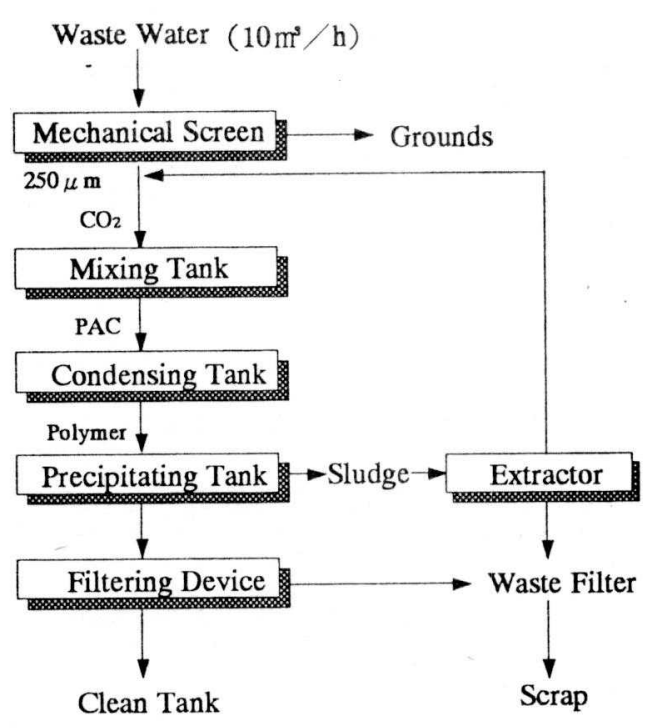

Figure 12 Flowchart of Water Recycle System

Table 3 Specification of Cleaning System

\begin{tabular}{|c|c|}
\hline \hline Object of Cleaning & $\begin{array}{c}\text { Aluminum Board } \\
4 \mathrm{~m}, 3 \mathrm{~m}, 2 \mathrm{~m}\end{array}$ \\
\hline Cleaning Ability & $\begin{array}{c}40 \text { pieces/h (low rate ) } \\
60 \text { pieces/h (high rate) }\end{array}$ \\
\hline Washing Method 11 & $\begin{array}{c}\text { Water Jet } \\
40 \mathrm{MPa}, 120 \mathrm{l} / \mathrm{min} . \\
\text { Rotating Nozzle }: 6\end{array}$ \\
\hline Washing Method 2 & $\begin{array}{c}\text { Ultrasonic Cleaning } \\
25 \mathrm{kHz}, 600 \mathrm{w}, 14 \mathrm{sets} \\
\text { Water tank }: 1 \mathrm{~m}^{3}\end{array}$ \\
\hline Capacity & 400 pieces/day \\
\hline
\end{tabular}

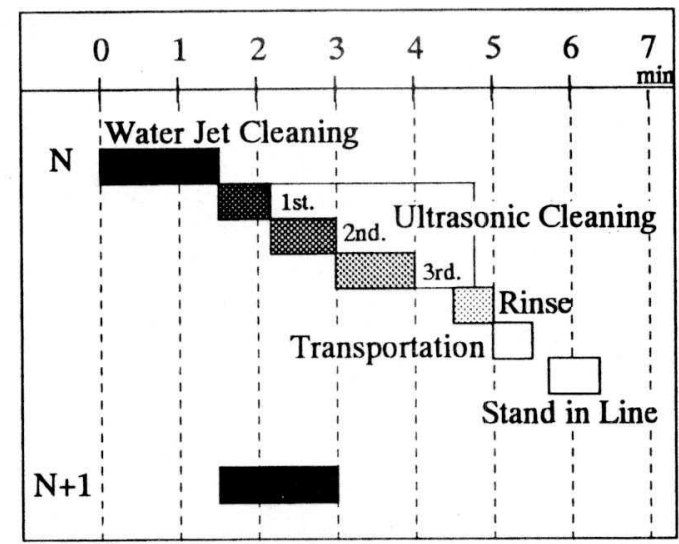

Figure 13 Timechart of Cleaning System 


\subsubsection{Evaluation of Washing Condition}

A finished condition of aluminum board after washing is objectively judged by image processing. A few of real images a board are sampled gray scale images digitized at 8 bits and they are binarized as white and black image.at a brightness intensity. These binarizations can distinguish the parts of fully cleaned area equal to white color from the parts of uncleaned area equal to black. An example of both real image and binarized image of a board are shown in Figure 14. By comparing the integrated white area with the all area, the finished condition is estimated in semi-empirical manner.

\subsection{Operating Condition}

Introducing the automated cleaning system to Obayashi Tokyo MaterialEquipment Center, it has been applied to actual work. Though many of aluminum board used at construction site are heavily dirty beyond expectation, this system has been certain to possess a enough ability to wash those boards. Figure 15 describes a comparison of cleaning performance. After washing, all the concrete paste and another dirt is certified to take off completely. At present, only one worker operates this system and more than four hundreds boards are washed carefully without damage.

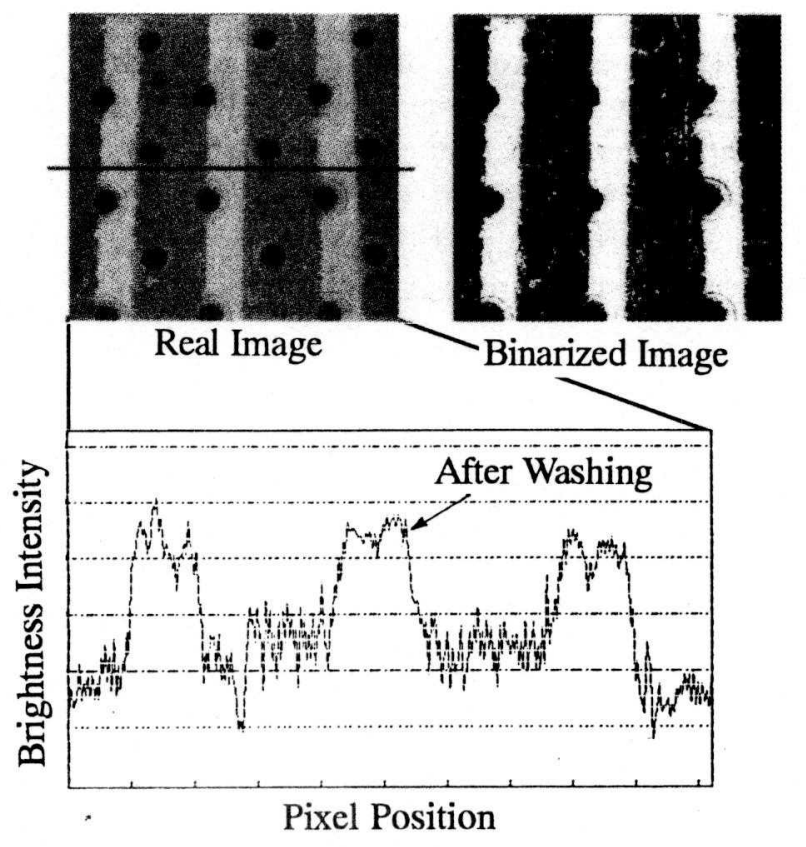

Figure 14 Evaluation of Image Processing

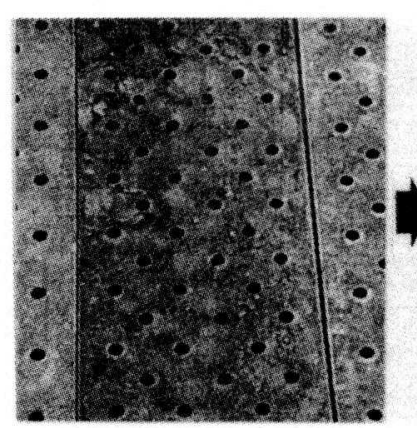

Before Washing

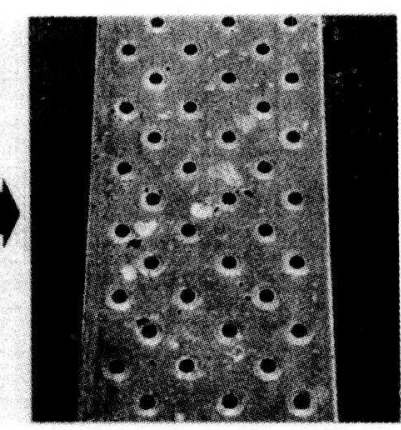

After Washing
Figure 15 Comparison of Cleaning Performance

\section{CONCLUSION}

The washing techniques, which are water jet cleaning and ultrasonic cleaning for aluminum scaffolding board, are verified by experimental study, and an automated cleaning system is developed with the these techniques. As a result of applying this system to actual work, the cleaning of aluminum board satisfying the initial specification can be performed favorably. The work efficiency become high and the work environment is also improved considerably.

Finally the authors would like to express their great appreciation to Mr. N.Sakaki and Mr.T. Andou in Obayashi Corporation for development support of this system. 